\title{
Neuropathic Pain in the Distribution of the Dorsal Nerve of the Penis Secondary to a Conus Medullaris Contusion
}

\author{
Hu Liang Low* and Ahsan Taqvi \\ Department of Neurosurgery, Queen's Hospital, United Kingdom \\ *Corresponding author: Hu Liang Low, Department of Neurosurgery, Queen's Hospital, United Kingdom
}

\begin{abstract}
Post-traumatic conus medullaris syndromes (CMS) such as after L1-burst fractures are uncommon, being encountered in only $1.7 \%$ of patients with spinal cord injuries. These injuries are almost invariably associated with bladder, erectile or bowel dysfunction, disturbance of perineal sensation and varying sensorimotor deficits in the legs. To date, there are only 6 reported cases of CMS after a L1-burst fracture without sensory or motor deficits in the lower limbs. In this case report, we describe a very rare case of CMS presenting as dysesthetic pain in the distribution of the dorsal nerve of the penis (DNP) and without leg weakness or numbness. Our observations suggest the sensory afferents of the adult human dorsal nerve of the penis terminates in the conus medullaris at levels corresponding to the middle of the T12/ $\mathrm{L} 1$ disc and the middle of the L1-vertebral body.
\end{abstract}

\section{Keywords}

Conus medullaris syndrome, Anatomy dorsal nerve of the penis, Thoracolumbar fracture, Incomplete spinal cord injury

\section{Introduction}

The conus medullaris ( $\mathrm{CM})$ is the tapered terminal portion of the spinal cord from which the sacrococcygeal nerve roots emerge. The $\mathrm{CM}$ is located as caudal as the L3 vertebral body prior to the age of 6-months but slowly ascends to the 'adult' level after the age of five where it is usually found extending from the level of the T12/L1 disc to the middle of the L1 vertebra $[1,2]$.

Insults to the $\mathrm{CM}$ can result in the combination of upper and lower motor neuron signs that make up the conus medullaris syndrome (CMS). The classical features of CMS include neurological deficits of the rectum and bladder, erectile dysfunction, sensory dis- turbances in the perineal area and sensorimotor deficits in the lower limbs. Many cases of CMS are incomplete and may be difficult to differentiate from a cauda equina syndrome (CES). Factors favoring the diagnosis CMS over CES include symmetrical sensory deficits, leg weakness and injuries to the T12-L2 vertebrae. CES is usually asymmetrical and never associated with injuries above the L3 vertebral level [2].

Post-traumatic CMS is uncommon, being reported in only $1.7 \%$ of spinal cord injured patients [3]. This may however been an underestimate given that the signs of CMS may be subtle [4]. CM injuries are more common following thoracolumbar burst fractures and may be present in up to $50 \%$ of cases [5]. CMS associated with L1-burst fractures almost invariably result in lower limb neurological deficits [5]. There are only 6 published cases to date of CMS due to L1 fractures with perineal and bladder disturbances but without lower limb sensory or motor problems [5,6].

We report a very rare case of CMS presenting as isolated dorsal penile pain without sensorimotor disturbances in the legs.

\section{Case Presentation}

A 45-year-old man complained of severe pain in his penis soon after falling off a ladder onto his back and was admitted under the trauma team. The pain was described as a combination of burning and tingling and contact between his underwear and his penis caused significant discomfort. He also had moderate lower back pain but this paled in comparison to his penile pain. The patient was able to stand and walk soon after

Citation: Low HL, Taqvi A (2019) Neuropathic Pain in the Distribution of the Dorsal Nerve of the Penis Secondary to a Conus Medullaris Contusion. Neurosurg Cases Rev 2:022. doi.org/10.23937/26434474/1710022

Accepted: September 03, 2019; Published: September 05, 2019

Copyright: (C) 2019 Low HL, et al. This is an open-access article distributed under the terms of the Creative Commons Attribution License, which permits unrestricted use, distribution, and reproduction in any medium, provided the original author and source are credited. 

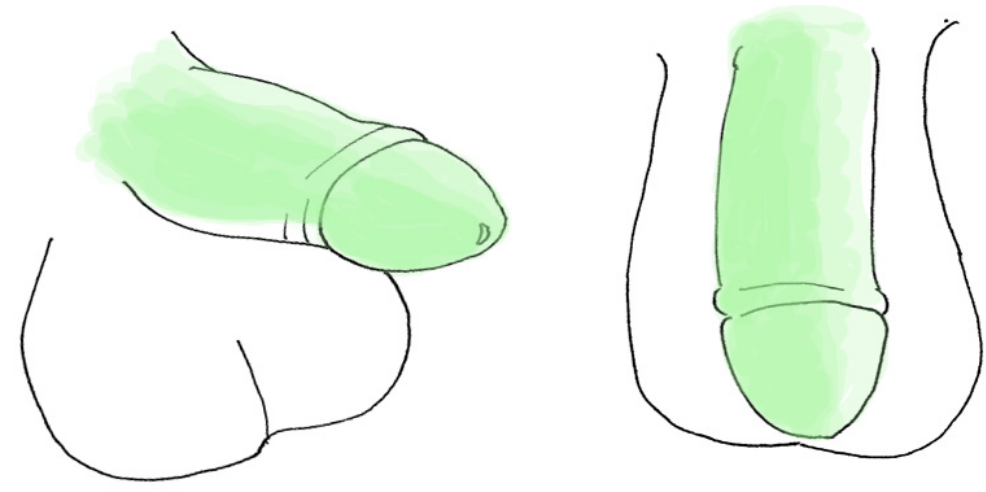

Figure 1: Schematic diagram of the penis as seen from the right and from above.

Areas of dysesthesia (shown in green) were confined to the dorsolateral shaft of the penis, the glans penis and the frenulum. The darker green areas denote regions where the pain was more intense. Note that a small area on the ventral aspect of the penis was not affected.

the injury.

On examination, the patient was in obvious distressed and was very reluctant to have his penis examined. He could not tolerate any contact between his penis and the overlying bed sheets. The area of pain was confined to the dorsolateral aspect of the penile shaft and the glans penis including the urethral meatus (Figure 1) but was more pronounced on the right. The painful area conformed to the cutaneous distribution of both dorsal nerves of the penis (DNP). Fine touch and pin prick sensation was present in the affected area but the sensation was distorted and the pain disproportionate to the stimulus strength (dysesthesia). Sensation in the ventral penis, scrotum and perineum was normal. There were no obvious external injuries involving his genitalia. Ankle jerks were absent bilaterally but knee, plantar and bulbocavernosus reflexes were normal. Anal tone, perineal, bladder and rectal sensation were normal. Satisfactory bladder emptying was achievable as shown on bladder scans but this act caused a "tearing" sensation only in the distal penis. He had mild bruising and moderate tenderness over the upper lumbar area. The remainder of his neurological and physical examination was unremarkable.

Abdominopelvic CT-scans followed by an ordinary MRI scan of the whole spine showed an L1-burst fracture (AO Type $A 3$ ) with mild reduction in vertebral height and no significant narrowing of the spinal canal diameter at L1. There was no obvious impingement of the conus medullaris from fracture fragments.

We suspected a partial CMS given the bilaterality of his signs (bilateral dorsal penile pain, loss of both ankle reflexes), no clinico-radiological evidence of pelvic or perineal injuries and an L1-burst fracture even though there was no obvious $\mathrm{CM}$ impingement by facture fragments. The MR scans were repeated with thinner slices from T11-L3 (1.5T Siemens Magnetom, $1.0 \mathrm{~mm}$ slices, 0 gap). Increased signal was seen in the $\mathrm{CM}$ on sagit-

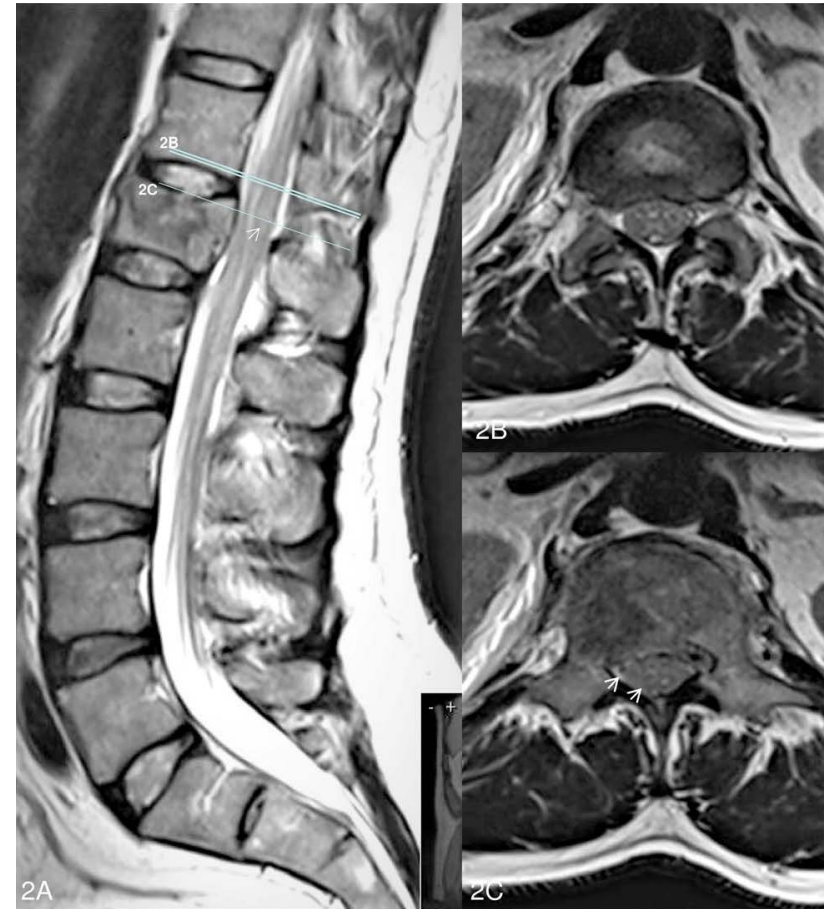

Figure 2: T2-weighted MRI images of the lumbosacral spine.

(A) Sagittal image showing the L1-burst fracture with minimal encroachment into the spinal canal. fracture. The lines $2 \mathrm{~B}$ and $2 \mathrm{C}$ corresponds to the level of images $2 \mathrm{~B}$ and $\mathrm{C}$ respectively. The arrowhead points to an area of increased signal within the conus medullaris; B) Axial T2-weighted MRI through the lower border of the T12 vertebral body which shows the typical X-shaped gray matter in the conus medullaris surrounded by white matter; C) Axial MR scan of the conus medullaris at the level of the $L 1$ fracture. There is edema and loss of differentiation between the gray and white matter of the conus medullaris on the right (arrowheads). The changes are more prominent on the right.

tal images as well as loss of differentiation between the gray and white matter in the $\mathrm{CM}$ from the middle of the T12/L1 disc to just rostral to the middle of the L1-vertebral body (Figure 2A and Figure 2B). The changes were more pronounced in the right hemicord (Figure 2C). The 
conus medullaris appeared normal rostral to the inferior end-plate of T12. The MR findings confirmed our suspicions. He was commenced on pregabalin $200 \mathrm{mg}$ tid for his pain. The fracture was treated conservatively by means of a well-fitting thoracolumbar orthosis, early mobilization and follow-up lumbar radiographs at 2- and 6-weeks to exclude movement of fracture fragments. He was nearly pain-free after 2-weeks and the orthosis removed at 12 -weeks after dynamic lumbar radiographs showed no obvious instability. One-year follow-up studies showed resolution of the changes within the conus medullaris and no evidence of spinal instability. Penile sensation and his ankle reflexes had returned to normal and he had no problems with bladder, bowel, leg or erectile function.

\section{Discussion}

Key to the understanding of the symptomatology of this case is knowledge of the anatomy of the dorsal nerve of the penis. The dorsal nerve of the penis (or clitoris) is a sensory nerve formed from the terminal division of the pudendal nerve (the other two branches being the inferior rectal and perineal nerves) within the pudendal canal. In this location, it lies in close to the inferior ischiopubic rami and emerges emerging from the pelvis by passing penetrating the urogenital diaphragm. In its extra-pelvic course, the DNP innervates the skin of the dorsolateral penile shaft (or its female equivalent), the corpora cavernosa and sends fibers through the spongy tissue of the glans penis to innervate the anterior urethra $[7,8]$. The distribution of the DNP explains our patient's symptoms and why he experienced anterior penile pain during micturition (due to anterior urethral stimulation). By contrast, the cutaneous territory of the perineal nerve is the ventral penile shaft, the posterior scrotum. The penile frenulum is jointly innervated by the perineal nerve and the DBP [8]. The inferior rectal supplies the perianal and posterior scrotal skin [9]. Pelvic pathology including inferior ischiopubic fractures can injure the DNP but due to the close proximity of pudendal nerve branches, isolated DNP injuries from pelvic pathologies must be very rare.

The central termination of the pudendal nerve is not well established in humans. Retrograde tracing techniques in animals show that that the pudendal motor efferents arise from a cell cluster in the ventrolateral horn known as Onuf's nucleus [10-12]. The human Onuf's nucleus is found principally in the S1-S3 spinal segments [13].

The spinal projection of pudendal sensory fibers in humans, especially those from the dorsal nerve of the penis, is unknown. In cats and monkeys, the pudendal sensory afferents project to the dorsal horns over a large area (L5 to S3 spinal segments in the cat [10] and L7 to S3 in macaque monkeys [12]). In rats, retrograde labeling techniques show that the fibers of the dorsal clitoral nerves (ie. the female homolog of the dorsal nerve of the penis) end in the L7 to S3 dorsal spinal horns [14]. Our case provides a unique opportunity to determine the central termination of the sensory fibers within the adult human DNP. In our case, thin-slice MRI scans revealed abnormalities within a small region of the $\mathrm{CM}$ extending from the level of the middle of the T12/L1 disc to the middle of L1-vertebral body with the more rostal cord appearing normal. Although the

Table 1: Summary of published cases of conus medullaris syndrome without lower limb sensorimotor disturbances following L1burst fractures.

\begin{tabular}{|c|c|c|c|c|c|}
\hline & $\begin{array}{l}\text { Age } \\
\text { (years) }\end{array}$ & $\begin{array}{l}\text { Mechanism of L1- } \\
\text { burst fracture }\end{array}$ & Initial findings & $\begin{array}{l}\text { Decompressive } \\
\text { surgery }\end{array}$ & Final outcome \\
\hline $\begin{array}{l}\text { Case } 1 \\
{[5]}\end{array}$ & 35 & Fall during skydiving & $\begin{array}{l}\text { Decreased scrotal and penile } \\
\text { sensation. Bladder distention }\end{array}$ & Yes & $\begin{array}{l}\text { Residual bladder, bowel } \\
\text { and erectile dysfunction at } \\
\text { 12-months }\end{array}$ \\
\hline $\begin{array}{l}\text { Case } 2 \\
{[5]}\end{array}$ & 41 & Fall during dune biking & $\begin{array}{l}\text { Urinary catheter. Decreased } \\
\text { scrotal sensation. Perianal } \\
\text { tingling }\end{array}$ & Yes & $\begin{array}{l}\text { Residual bladder, bowel } \\
\text { and erectile dysfunction at } \\
\text { 15-months }\end{array}$ \\
\hline $\begin{array}{l}\text { Case } 3 \\
{[5]}\end{array}$ & 38 & Fall from tree & $\begin{array}{l}\text { No details of bladder function } \\
\text { or perineal sensation }\end{array}$ & Yes & $\begin{array}{l}\text { Residual bladder, bowel } \\
\text { and erectile dysfunction at } \\
\text { 1-months }\end{array}$ \\
\hline $\begin{array}{l}\text { Case } 4 \\
{[5]}\end{array}$ & 28 & Motor vehicle accident & $\begin{array}{l}\text { Delayed ( } 7 \text { days) perineal and } \\
\text { bladder dysfunction }\end{array}$ & No & $\begin{array}{l}\text { Normal bladder, bowel and } \\
\text { erectile function at } 6 \text {-months }\end{array}$ \\
\hline $\begin{array}{l}\text { Case } 5 \\
{[6]}\end{array}$ & 73 & Fall & $\begin{array}{l}\text { Delayed ( } 2 \text { months) perineal, } \\
\text { bladder and bowel dysfunction }\end{array}$ & Yes & $\begin{array}{l}\text { Normal bladder and bowel } \\
\text { function and perineal } \\
\text { sensation at 12-months }\end{array}$ \\
\hline $\begin{array}{l}\text { Case } 6 \\
{[18]}\end{array}$ & 25 & Motor vehicle accident & Bladder dysfunction & Yes & $\begin{array}{l}\text { Normal "sphincter function" } \\
\text { at an average follow-up of } \\
\text { 30-months }\end{array}$ \\
\hline $\begin{array}{l}\text { Case } 7 \\
\text { (present } \\
\text { case) }\end{array}$ & 45 & Fall from ladder & Dorsal penile pain & No & $\begin{array}{l}\text { Normal bladder, bowel and } \\
\text { erectile function and perineal } \\
\text { sensation at } 12-\text { months }\end{array}$ \\
\hline
\end{tabular}


possibility of microscopic damage rostral to this level cannot be fully excluded, we believe that the majority of DNP fibers terminate in the dorsal horn of the adult human conus medullaris at levels corresponding to the middle of the T12/L1 disc and the rostral half of the L1-vertebral body. Indirect corroboration of our hypothesis comes from two studies whereby the epidural stimulation of the conus medullaris was carried out to control refractory pudendal neuralgia $[15,16]$. In both studies, stimulation via epidural leads were placed at the level of the T12- L1 vertebral bodies resulted in significant improvements in pudendal neuralgia.

The management post-traumatic CMS is similar to that for any patient with a suspected spinal injury [1719]. The management once the patient is stabilized is a case of continuing debate with proponents for and against surgical intervention [18-19]. These arguments are likely to continue until the natural history of posttraumatic CMS and the factors that determine its progression and final outcome are better understood. Table 1 summarizes the key features of the published cases of CMS without sensorimotor disturbances in the legs. It is apparent that decompressive surgery does not always equate with a better long-term outcome.

In our case, we opted for conservative treatment as his symptoms were non-progressive, there was no obvious impingement upon the $\mathrm{CM}$ by a fracture fragment and because his fracture was considered relatively 'stable'. Our treatment plan was vindicated by the complete resolution of all symptoms at 1-year but this may not be applicable to all cases. This emphasizes the need for treating physicians to customize their treatment given the present limited evidence for any of the treatment modalities used in incomplete cord injuries [19].

\section{Conclusion}

Post-traumatic conus medullaris syndromes are rare but should always be considered in patients with T12-L2 fractures especially if they have neurological disturbances involving the bladder and bowel, genitalia and legs and the absence of significant pelvic trauma.

\section{Competing Interests}

The authors have no competing interests to declare.

\section{References}

1. Jung JY, Kim EH, Song IK, Lee JH, Kim HS, et al. (2016) The influence of age on positions of the conus medullaris, Tuffier's line, dural sac and sacrococcygeal membrane in infants, children, adolescents and young adults. Paediatr Anaesth 26: 1172-1178.

2. Brouwers $E$, van de Meent $H$, Curt A, Starremans B, Hosman A, et al. (2017) Definitions of traumatic conus medullaris and cauda equina syndrome: A systematic literature review. Spinal Cord 55: 886-890.

3. McKinley W, Santos K, Meade M, Brooke K (2007) Incidence and outcomes of spinal cord injury clinical syndromes. J Spinal Cord Med 30: 215-224.
4. Watanabe $T$, Vaccaro AR, Kumon $H$, Welch WC, Rivas DA, et al. (1998) High incidence of occult neurogenic bladder dysfunction in neurologically intact patients with thoracolumbar spinal injuries. J Urol 159: 965-968.

5. Chou D, Hartl R, Sonntag VK (2006) Conus medullaris syndrome without lower extremity involvement in L-1 burst fractures: Report of four cases. J Neurosurg Spine 4: 265269.

6. Tanaka S, Kubota M, Fujimoto Y, Hayashi J, Nishikawa K (1993) Conus medullaris syndrome secondary to an L1 burst fracture in osteoporosis. A case report. Spine 18: 2131-2134.

7. Yang CC, Bradley WE (1998) Neuroanatomy of the penile portion of the human dorsal nerve of the penis. $\mathrm{Br} \mathrm{J} \mathrm{Urol}$ 82: 109-113.

8. Yang CC, Bradley WE (1999) Innervation of the human glans penis. J Urol 161: 97-102.

9. Shafik A, Doss S (1999) Surgical anatomy of the somatic terminal innervation to the anal and urethral sphincters: Role in anal and urethral surgery. J Urol 161: 85-89.

10. Ueyama T, Mizuno N, Nomura S, Konishi A, Itoh K, et al. (1984) Central distribution of afferent and efferent components of the pudendal nerve in cat. J Comp Neurol 222: 38-46.

11. Roppolo JR, Nadelhaft I, De Groat WC (1985) The organization of pudendal motoneurons and primary afferent projections in the spinal cord of the rhesus monkey revealed by horseradish peroxidase. J Comp Neurol 475-488.

12. Ueyama T, Mizuno N, Takahashi O, Nomura S, Arakawa $\mathrm{H}$, et al. (1985) Central distribution of efferent and afferent components of the pudendal nerve in macaque monkeys. $J$ Comp Neurol 232: 548-556.

13. Pullen AH, Tucker D, Martin JE (1997) Morphological and morphometric characterisation of Onuf's nucleus in the spinal cord in man. J Anat 191: 201-213.

14. Martin-Alguacil N, Schober JM, Sengelaub DR, Pfaff DW, Shelley DN (2008) Clitoral sexual arousal: Neuronal tracing study from the clitoris through the spinal tracts. J Urol 80: 1241-1248.

15. Buffenoir K, Rioult B, Hamel O, Labat JJ, Riant T, et al. (2015) Spinal cord stimulation of the conus medullaris for refractory pudendal neuralgia: A prospective study of 27 consecutive cases. Neurourol Urodyn 34: 177-182.

16. Reichart R, Kuhn SA, Vogel I, Walter J, Kalff R (2009) Spinal cord stimulation at the level of the conus medullaris: Treatment option for therapy-resistant postoperative neuralgia of the pudendal nerve. Schmerz 23: 640-644.

17. Dall BE, Stauffer ES (1988) Neurologic injury and recovery patterns in burst fractures at the T12 or L1 motion segment. Clin Orthop Relat Res 233: 171-176.

18. Kingwell SP, Curt A, Dvorak MF (2008) Factors affecting neurological outcome in traumatic conus medullaris and cauda equina injuries. Neurosurg Focus 25: E7.

19. Divi SN, Schroeder GD, Mangan JJ, Tadley M, Ramey WL, et al. (2019) Management of acute traumatic central cord syndrome: A narrative review. Global Spine J.
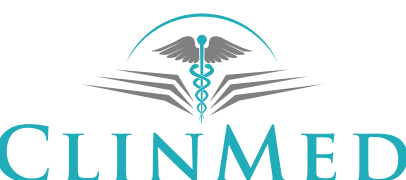

INTERNATIONAL LIBRARY 